\title{
UK Renal Registry 12th Annual Report (December 2009): Appendix J Renal Centre Names and Abbreviations used in the Figures and Data Tables
}

Adult Centres

\begin{tabular}{|c|c|c|c|}
\hline City & Hospital & Abbreviation & Country \\
\hline Birmingham & Heartlands Hospital & B Heart & England \\
\hline Bradford & St Luke's Hospital & Bradfd & England \\
\hline Brighton & Royal Sussex County Hospital & Brightn & England \\
\hline Bristol & Southmead Hospital & Bristol & England \\
\hline Carshalton & St Helier Hospital & Carsh & England \\
\hline Chelmsford & Broomfield Hospital & Chelms & England \\
\hline Colchester & Colchester General Hospital & Colchr & England \\
\hline Coventry & Walsgrave Hospital & Covnt & England \\
\hline Derby & Royal Derby Hospital & Derby & England \\
\hline Doncaster & Doncaster Royal Infirmary & Donc & England \\
\hline Hull & Hull Royal Infirmary & Hull & England \\
\hline Ipswich & Ipswich Hospital & Ipswi & England \\
\hline Kent & Kent and Canterbury Hospital & Kent & England \\
\hline Leeds & St James's University Hospital and Leeds General Infirmary & Leeds & England \\
\hline Leicester & Leicester General Hospital & Leic & England \\
\hline Liverpool & University Hospital Aintree & Liv Ain & England \\
\hline Liverpool & Royal Liverpool University Hospital & Liv RI & England \\
\hline London & St Barts and The London Hospital & L Barts & England \\
\hline London & St George's Hospital & L St. G & England \\
\hline London & Guy's \& St Thomas' Hospital & L Guys & England \\
\hline London & Hammersmith, Charing Cross, St Marys' and Paddington Hospitals & L West & England \\
\hline London & King's College Hospital & L Kings & England \\
\hline
\end{tabular}

\section{KARGER \\ Fax +4161306 1234 E-Mail karger@karger.ch} www.karger.com
(C) 2010 S. Karger AG, Basel

$1160-2110 / 10 / 1155-0368 \$ 26.00 / 0$

Accessible online at: www.karger.com/nec
UK Renal Registry, Southmead Hospital, Southmead Road, Bristol BS10 5NB, UK

Email: renalreg@renalreg.com 


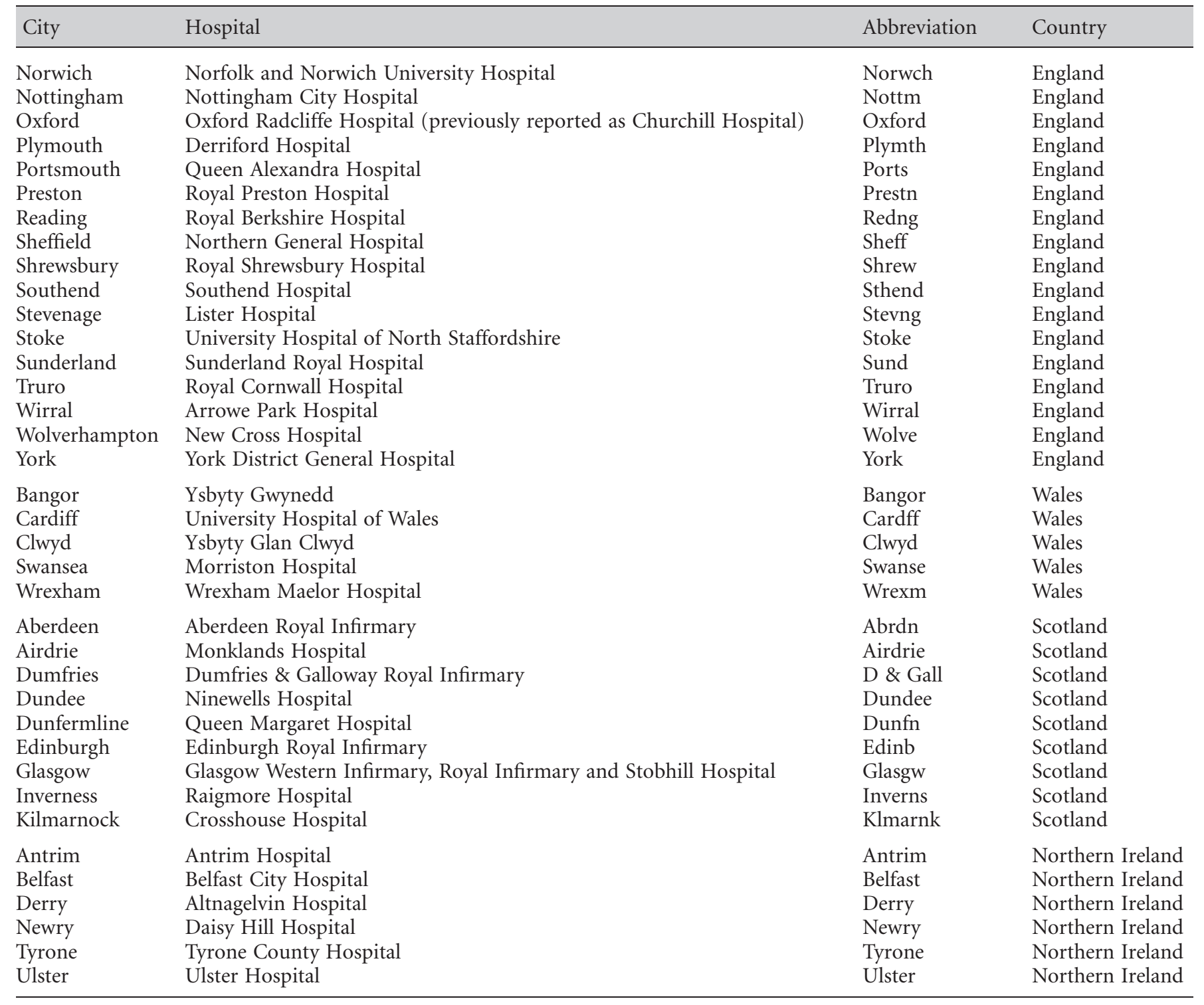

\section{Paediatric Centres}

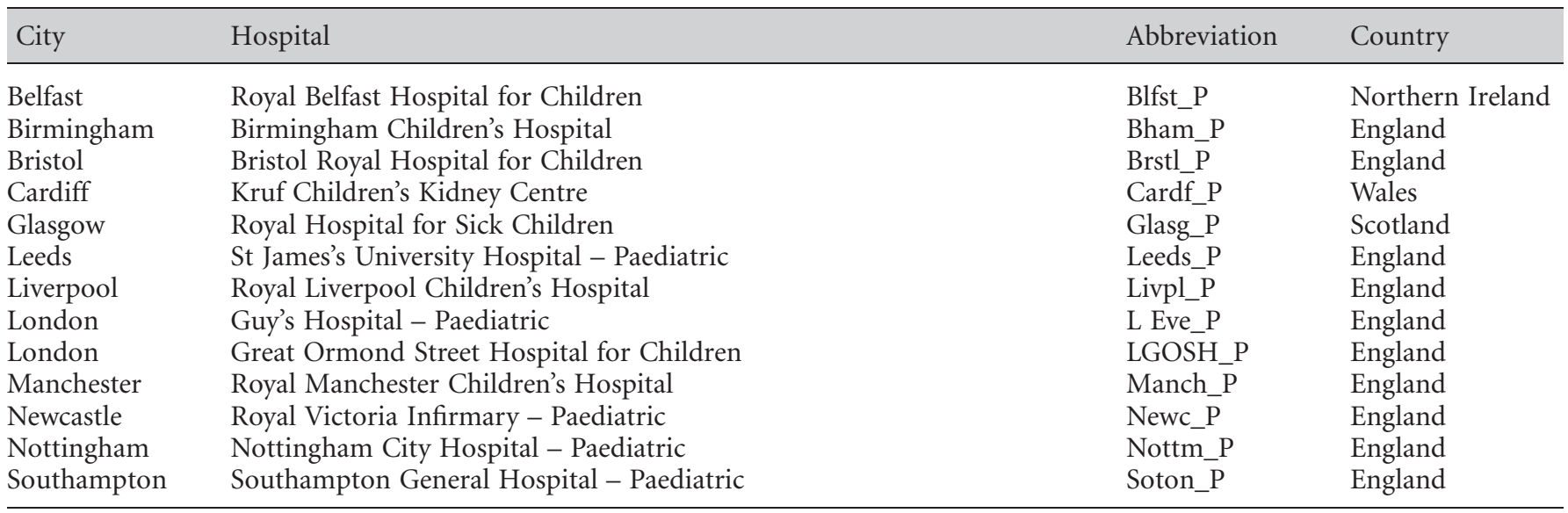

